\title{
Body and self: an entangled narrative
}

\author{
Priscilla Brandon
}

(C) Springer Science+Business Media Dordrecht 2014

In the past three decades a number of narrative self-concepts have appeared in the philosophical literature. A central question posed in recent literature concerns the embodiment of the narrative self. Though one of the best-known narrative self-concepts is a non-embodied one, namely Dennett's self as 'a center of narrative gravity', others argue that the narrative self should include a role for embodiment. Several arguments have been made in support of the latter claim, but these can be summarized in two main points. Firstly, a logical one: without taking the body into account Dennett's theory becomes selfrefuting. Secondly, a more practical/phenomenological point: a disembodied self-concept overlooks how personal the body is, and as such should be considered part of the self. In this paper I endorse these criticisms of non-embodied narrative self-concepts, but I argue that the relationship between the narrative self and the body is far from sufficiently fleshed out. I claim that the narrative self and the body are much more interwoven than the above criticisms suggest. What I aim to show in this paper is that the relationship between the body and the narrative self is interactive rather than unidirectional: not only does our body shape our narrative self, but our narrative self also shapes our body. The upshot of this is a better conception of the self is as a dynamic interaction between its various aspects.

Keywords Narrative self-concepts · Embodiment of self

\section{Introduction}

Since the late 1980s, narrative self-concepts have attracted a great deal of attention in debates about the self. There is a lack of clarity about the notion of 'the narrative self' in these debates, which is partly due to the fact that different authors have different research interests. Often the narrative self-concept is presented as an alternative to analytic approaches to the self, which are guided by the question as to what may account for personal continuity. ${ }^{1}$ Rather than defining personal identity through time in

\footnotetext{
${ }^{1}$ The narrative self has been presented as such by Mackenzie and Atkins (2008), Marya Schechtman (1996; 2007) and Ricoeur (1992).

P. Brandon $(\triangle)$

Department of Philosophy Erasmusplein 1, Radboud University Nijmegen, Nijmegen 6500 HD, The

Netherlands

e-mail: p.brandon@ftr.ru.nl
} 
impersonal terms, defenders of the narrative to take the irreducible first-personal character of experience into account, as well as self-interested concern and daily practices that pertain to the self. For our interest in our self is based on precisely these experiences and practical, evaluative, concerns. Narrativity then serves as a practical form of continuity, tying questions of 'Who?', 'What?', 'Where?', 'When?', and 'Why?' into a story that forms a person's identity. Very different from these accounts, though just as often referred to, is Dennett's fictional narrative self that serves as a stand-in for the self as a (meta) physical entity that we can no longer believe in.

The discussion as to whether the narrative self is an adequate self-concept is an ongoing one, and various arguments have been made against it. The focus of this paper is on one important such criticism, namely, the arguments that pertain to the role of the body in the narrative self-concept. Most of the well-known narrative self-concepts pay little attention to embodiment (cf. Schechtman 1996; Taylor 1989), or go to the extreme of stating that the narrative self is abstract and hence not embodied (Dennett 1991). Opposing this, some have argued that the body is needed as a foundation for the narrative self, and additionally, others have argued that the body should be considered as a part of the self. ${ }^{2}$

I agree with both of these points, but contend that the body and narrative self should be much more interwoven than these embodied narrative self-accounts suggest. For, currently, the relationship remains unidirectional, that is, the narrative self is presented as the 'result' or the 'output' of the body and experiences. Yet the narrative self feeds back into our body, the upshot of which is that the relationship between the narrative self and body is interactive. The existence of this interaction ultimately leads to the argument that we should view the self as an interaction between various elements.

In order to present and defend these claims, I firstly discuss the contrasting positions from the debate. I begin in the next section (2) with an explanation of Dennett's selfconcept. His narrative self-concept has been the target of several criticisms concerning the relationship to the body. In the third section I present these criticisms, taken together as two main points. Firstly, a logical point: without a body, the account becomes selfrefuting; secondly, a more practical or phenomenological one: a disembodied selfconcept overlooks how personal the body is, and as such should be considered part of the self. Next, in section four, I explain what I find lacking in the accounts discussed thus far, and how we can better understand the relationship between the narrative self and the body as interactive. At this point, I also present my ideas on how the concept of 'narrative self' can be refined. The fifth section presents a case illustration from psychotherapy that provides concrete insight into the interaction between our narrative self and the embodiment which I wish to defend. Finally, in the sixth section, I provide a rudimentary sketch of the link between the view of narrative selfhood that I defend in this paper and conclusions resembling this claim that can be found in some views in feminist philosophy and in the debate on social cognition, respectively. This resemblance demonstrates how my notion of the narrative self resembles ideas on the self that many scholars (albeit in other fields) have already accepted. I then conclude with insights into the relevance of my defence of the interactive view of the narrative self as an entanglement of body and self.

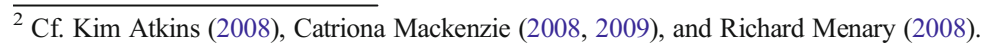




\section{Dennett's self as a center of narrative gravity}

Dennett's narrative self is often presented as a prototypical narrative self-concept, even though many philosophers who are sympathetic to narrative self-views are critical of his work. Dennett presented his narrative self-concept as part of his studies of consciousness, as set out in Consciousness Explained (1991, hereafter: CE). One of Dennett's key targets in $C E$ is a Cartesian notion of the self, or any sort of dualistic thinking for that matter; either in the form of the metaphysical notion of a nonmaterial self, or in the form of a 'Central Meaner' - a place in the brain where everything comes together and is coordinated. Neuroscience has discovered no such center in the brain, but rather, only a manifold of simultaneous processes, none of which guards all others. Claiming that there must be some sort of 'Central Meaner' betrays an attachment to a concept of the soul, cloaked in a material form. From this materialistic perspective, and with this Cartesian notion of the self in mind, Dennett draws the conclusion that there are no such things as (Cartesian) selves. What does exist, is the narrative self. This self has no material extension in the world, but exists as a fiction, in the same way as fictive characters like Sherlock Holmes exist, or theoretical abstractions such as centers of narrative gravity (Dennett 1992, 103-104).

To clarify this counterintuitive notion of the self, Dennett asks us to imagine a robot that is in possession of a story-writing program. The robot says: "Call me Gilbert." Rolling its way through the world, the robot encounters several situations: it is hit by a ball, it accidentally gets locked up in a closet, etc. And during these events, it reports via its storytelling program ("Yesterday I got locked up in a closet"). Accordingly, the robot collects stories based upon the input from its encounters, thereby forming an autobiography that refers to Gilbert; the self that the robot has created. Gilbert is the product of a bundle of processes in which the self takes no part:

the robot's brain, the robot's computer, really knows nothing about the world; it is not a self. It's just a clanky computer. It doesn't know what it's doing. It doesn't even know that it's creating this fictional character. (The same is just as true of your brain; it doesn't know what it's doing either.) (Dennett 1992, 108)

Here, Dennett leads us to the conclusion that we function in a similar way to the robot Gilbert. No self whatsoever precedes the narrative fiction that our brain creates. Instead, our self is also a product of something that is not a self, i.e. the brain, and hence when referring to itself, it refers to a self that only exists in its own autobiography. ${ }^{3}$ The narrative self is a theoretical construct, referring only to an abstract ' $\mathrm{I}$ ' that functions in the various narratives:

And where is the thing your self-representation is about? It is wherever you are. [...] And what is this thing? It's nothing more than, and nothing less than, your center of narrative gravity." (Dennett 1991, 429)

\footnotetext{
${ }^{3}$ As for the fictional status of the self, Dennett claims that whether the narrative from a narrative self refers to factual situations does not change this status. After all, this status is based on the false suggestion that the narrative creates an existence of the self outside of this narrative (Dennett 1992, 107-108).
} 
So how does the body relate to this narrative self? The brain is needed to create the narrative self, but the abstract self that thereby comes into existence obviously does not contain anything physical. This lack of embodiment of the self is also apparent in a somewhat strange literal sense, as Dennett explains:

"Call me Dan", you hear from my lips, and you oblige, not by calling my lips Dan, or my body Dan, but by calling me Dan, the theorists' fiction created by... well, not by me but by my brain, acting in concert over the years with parents and siblings and friends. (Dennett 1991, 429; my italics [PB]).

Note that as a consequence of its impersonal role in the constitution of the self, the body is only contingently connected to the self; it forms no intrinsic part of it. That is why Dennett can claim that a self, in principle, can survive without a body, analogous to a computer program surviving the demolition of the computer on which it was first run, as long as it has been transferred to another disk (Dennett 1991, 430). With this sketch of Dennett's narrative self in place, I now turn to arguments that have been put forward criticizing his self-concept.

\section{Two arguments against the non-embodied narrative self}

Dennett's concept can be and has been criticized for various reasons, however for the purposes of this paper I focus on the criticism that is concerned with the relationship of the narrative self to the body. From the depiction of Dennett's account of the self, an abstract point where various narratives intersect, we can conclude that this self is not bodily. Two lines of argument can be distilled as to why the body should in some way be considered a part of the self: one pertains to the lack of consistency of a disembodied self-concept; the other pertains to the importance, and hence implausible neglect, of the body as a personal part of the self. In the next two sections I review both arguments, respectively in turn.

\subsection{A disembodied narrative self is a self-refuting concept}

From rather diverse angles several thinkers argue that there is a non-narrative part of the self without which a narrative theory of the self becomes self-refuting. Dennett's selfconcept has been criticized based on this line of thought. For a self that comes into existence through reflection raises the question of where this self comes from. Whose story is it that is being narrated? And how do we know that it is our narrative rather than someone else's, if there is nothing specifically 'self'-like about our body, our thoughts, or our experiences to recognize it as such? ${ }^{4}$

As to what exactly it is that needs to precede the narrative, opinions seem to differ or at least the vocabulary does - but many accounts focus on some form of

\footnotetext{
${ }^{4}$ This point has been made, for instance, by Zahavi (2007) and Mackenzie (2008), and also by Velleman (2006), who claims that the idea of a self coming into existence through its self-constituting power is a paradox. However, Velleman believes that Dennett is the one philosopher who escapes this paradox of selfconstitution by embracing it. We do invent ourselves, and thus create an illusion of an autonomous self (2006, 203-206).
} 
embodiment. ${ }^{5}$ Since philosophers with different backgrounds target the problem of a disembodied narrative self-concept, and moreover have done so I to address different kinds of field-specific problems and cases, it may not at first be apparent that they are fundamentally concerned with the same problem. I will therefore present two critical arguments against full-blown narrative self-concepts from rather different angles: the accounts of Tim Thornton and Dan Zahavi (Thornton -2003; Zahavi 2005, 2007).

Thornton approaches the question of the self - or personal identity - from the analytic tradition; that is, as the question concerning the conditions for diachronic selfidentity. Concerned with the philosophy of psychiatry, Thornton examines two accounts of narrativity, evaluating their potential worth for understanding psychopathological cases. Thornton compares Dennett's 'austere account of the self' with an embodied narrative account, which he assembles from the writings of Strawson (1959), McDowell (1998), and Slors (1998). Although Thornton finds Dennett's account attractive in its ability to explain the occurrence of some psychopathological phenomena in a straightforward manner, in the status of the self as a non-embodied fiction, he detects an insolvable problem. As I noted earlier, in Dennett's account, thoughts and perceptions expressed in the narrative do not (indirectly) refer to a subject. This, however, seems to be problematic. Referring to Campbell (1994), Thornton explains that many psychological verbs, such as 'being in pain', are conceptually dependent on a reference to a person. When being in pain refers to our self, we do not apply that concept in any third-person observational way, but ascribe it directly, simply on the strength of our subjective experience of being in pain (Thornton 2003, 363). Therefore, we need to be able to directly experience our selves as the subject of pain, the ones who are in pain. As such, Thornton does not see how a reductionist account such as Dennett's can escape the criticism of lacking of a possibility of direct reference to our self. ${ }^{6}$

Thornton then discusses the alternative of an embodied account, wherein the self, or the 'subject', does not solely consist in a narrative. According to this view, embodiment is important for the generation of a narrative, since "being embodied contributes to the rational structure of experiences and thoughts" (Ibid, 365). As an 'object' moving through the world, bringing a flow of changing perception and thought with it, the body already provides a logical sequence for a possible story and gives shape to the continuity and rational underpinning of the narration of the self's experience. Narrative unity functions here as the psychological counterpart of embodied continuity; it structures our thoughts in a meaningful way, creating a sensible whole. Thus, in conjunction with embodiment, narrative plays an enabling role for the self's

\footnotetext{
${ }^{5}$ Critiques that refer to the need of embodiment and/or alternative embodied narrative self-concepts come, for instance, from Kim Atkins (2008), Catriona Mackenzie (2008, 2009), and Richard Menary (2008). There are, however, exceptions to this claim of necessary embodiment. Lynne Rudder Baker, for instance, is one of the defenders of the need for an embodied, first-person self-experience that forms the basis for any narrative self; however, she wants to allow for the possibility of persons without human bodies (Baker 2000; in Atkins \& Mackenzie 2008). Also Ricoeur, whose view of the narrative self is initially closely connected with the phenomenological embodied experience, eventually argues for a self-notion (self as a pure identity pole) that is neither embodied nor contextualized (Ricoeur 1992).

${ }^{6}$ As Thornton conclude, the alternative would be to take the Lichtenbergian attempt to claim "It is thinking" seriously, ' $[\mathrm{b}]$ ut as the history of solipsism suggests, given this starting point, there is no hope of a recovery of other subjects of experience (cf. Strawson 1959). Either way, a reductionist approach looks doomed.' (2003, 363.)
} 
articulation. This may sound similar to Dennett's account, for as Dennett explained, Gilbert also - as do we - receives input from physical encounters in the world, providing a logical sequence for a narrative. The crucial difference is that, in contrast to Dennett's version, the input to a narrative in this case consists of perceptions, experiences, and thoughts that are already tied to a self (Ibid, 366). Hence, the body is considered to be part of the experiential subject and the problem of the apparent lack of a subject of experience thus no longer applies.

From a wholly different direction than the analytical identity debate, Zahavi evaluates the narrative self-concept from a phenomenological tradition. Though Zahavi is sympathetic to the idea of a narrative dimension or aspect of the self, he criticizes selfconcepts that consider the self to be solely a narrative (abstraction) Zahavi (2005, 2007). Zahavi finds it an oversimplification to take the self as a univocal concept. To this end, he calls attention to an aspect of the self, which in recent years has received attention from neuroscientists such as Damasio and the philosopher Metzinger, but can be traced back to the writings of phenomenologists such as Husserl, Sartre, MerleauPonty, and Henry. ${ }^{7}$

These earlier thinkers found consciousness to be characterised by a fundamental self- or first person-givenness, also referred to as the 'experiential dimension of selfhood' (Zahavi 2007, 186-187). This refers to all of our experiences, bodily sensations, emotional states, and cognitive contents being accompanied by a sense of implicit 'mineness': we experience everything from a first-person perspective. This experienced selfhood, which precedes any reflection on the self, accompanies all experience as an invariant dimension of the structure of experience. So, although our experiences vary widely, from smelling food, to hearing noise or music, to the feeling of sliding into a bath, or having muscle pain, - these experiences are invariably firstperson given. This is what makes experiences subjective. We do not experience pain, for example, and then need to wonder to whom this experience of pain actually belongs. Note that this experiential notion of the self is therefore not something that is laid on top of experience, but rather is fully immersed in our experiential life. It would thus be mistaken to interpret this phenomenological notion of the self as a Cartesian residuum, some sort of enclosed mental interiority (Ibid, 189).

Again, how does this differ from Dennett's notion of the self? Dennett acknowledges that we experience our body not just as a random object in the world, but in a specific manner such that we can directly distinguish it from other objects in the world. However, Dennett emphasizes that we should not consider this 'first-person experience' of our body as some sort of (part of our) self: after all, our self is an abstract point of narrative gravity. Here Dennett appears to agree with Metzinger, and this is where they both part company with Zahavi, or, for that matter, Damasio, since the latter two both claim that this experiential dimension of the self should be included in a selfconcept.

Zahavi therefore rejects the notion of the self as a narrative construction, along with the notion that narratives provide the only access to the self. In addition to the fact that the experiential dimension of the self is an integral part of our experience, it must, moreover, be regarded as a "pre-linguistic presupposition for any narrative practice" (Ibid, 191). After all, only a being with a first-person perspective is able to regard his/

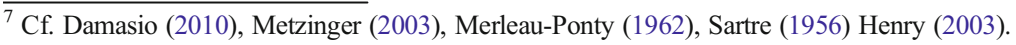


her experiences as his/her own and narrate them. Zahavi therefore suggests we make a distinction between a basic first-person perspective that provides direct access to our experiential life on the one hand, and, on the other, a stronger first-person perspective that is able to articulate our experiences in narration. ${ }^{8}$

To accept this point is to adopt the view that "even this primitive and foundational structure merits the name of self' (Ibid), something which, according to Zahavi, is not sufficiently recognized by many defenders of the narrative view of the self. Clearly the underlying concern is not so much what deserves to be labelled a 'self'; rather, the point is that there is a non-narrative aspect of the self, an embodied subject of experience. ${ }^{9}$

To conclude, although they represent very different philosophical traditions, both Thornton and Zahavi argue that the narrative self is in need of a non-narrative aspect, an embodied subject of experience that provides a necessary foundation for the narrative self. Notably, the role of the body in Thornton, as well as in Zahavi's argument, remains rather abstract. However, other philosophers who problematise the disregard of our embodiment take a more practical approach. They argue that the disembodied narrative self-concept is flawed because our body forms an undeniable part of our self. If we want to come to an accurate description of the self as it functions in our daily lives, the body, which is fully personal, cannot be left out. It is to this second line of argument that I now turn.

\subsection{The body is part of the self}

In a paper that compares the abstract narrative accounts of Dennett and Velleman to embodied narrative accounts, for example those of Atkins and Mackenzie, Menary (2008) is critical of Dennett's abstract self. Menary first points to the problem of reference that is also brought up by Thornton, but proceeds to place strong emphasis on the missing embodied subject that is so obviously there in our everyday experience. Menary illustrates this point with an example of when he was hit by a cricket ball, arguing that it would sound wrong to say that he's ascribing the pain to a collection of narratives. Rather, he himself is the one that feels pain: "the narrative is about a subject who feels pain, and that subject who feels is me" (Menary 2008, 73). Menary concludes that:

[t] he self is not simply a narrative construct; it perceives, thinks, and acts. The self is the entire human organism including its narratives and this should be the starting point for any account of the self (Ibid), and later: "The self is, at least in part, a body" (p79).

Mackenzie is another philosopher who argues that the narrative self needs to be embodied, though her argument is not particularly directed against Dennett's. Mackenzie (2008) makes her case for embodiment in contrast to the often-cited narrative

\footnotetext{
${ }^{8}$ According to Zahavi this distinction can also make more sense of what we consider to be selves in (our) daily life lives, for it is not the case that we consider an individual as a self only once a narrative is in place. For instance, very young children are not able to articulate their experiences, yet we would not deny them a self. This point is also made by Menary $(2008,66)$.

${ }^{9}$ I understand Zahavi's experiential dimension of the self to be intrinsically connected to our embodiment, not only because he explicitly distances his position from any Cartesian notion of an inner mental entity, but also because of the explication of his position in The phenomenological mind (2005), co-written with Shaun Gallagher. Cf., p.8; p.27; p.33: '...the starting point, on the phenomenological side, is with embodied, in-theworld experience, rather than with an intellectualized version of experience.'
} 
account of Schechtman (1996; 2007). In her work, Schechtman characterizes subjectivity solely in psychological terms and reserves the body solely for the third-person (re-) identification of subjects. In contrast to this account, Mackenzie argues that subjectivity is psychological and embodied (2008; 2009).

Similar to the other critics, Mackenzie states that our "lived bodily experience" is a condition of possibility of our narrative, being "the perspective from which we perceive the world and as our mode of engagement with it." $(2009,116)$ Different from Menary, Mackenzie goes on to further explicitly stress the relevance of the body beyond a structural necessity; she pays attention to the very subjectivity of our body as it incorporates the sedimentation of our personal past through our acquired skills and habits, bodily postures and gestures. Our bodily experience includes how we represent our body to ourselves in our beliefs about it, as well as our emotional attitude toward it (Ibid, 117). Hence, aspects of our bodily lives shape our self-image and thus also our narrative identity. Mackenzie illustrates this with an example: "a thin young man's representation of himself as puny and scrawny may change over time into a representation of himself as lean, wiry, and fit as he develops into a cross-country runner." (Ibid)

Mackenzie thus forms an exception in the debate, together with for example Atkins (2004; 2008), in lending more substance to the embodiment of the narrative self. This differs from the accounts of Thornton and Zahavi, in which the embodiment of the narrative self remains on an abstract level. In these abstract accounts, the body is first and foremost presented as a constitutive precondition for the development of a narrative self. On the other hand, in addition to its conditional role, thinkers such as Mackenzie have argued that the body is thoroughly personal, influencing our self-image and thus our narrative identity.

I fully recognize the relevance of all of the above points; indeed, our embodiment is constitutive of our more robust personal identity, and our narrative is shaped by the specific characteristics of our embodiment. ${ }^{10}$ But I think the relationship between the body and the narrative self thus far presented is not sufficiently integrated. One crucial aspect that is largely neglected in the debate is the influence of the narrative self-image on the body. In the accounts sketched above, the focus remains on how the body is constitutive for, and shapes, the self; they do not include the inverse: how the narrative or self-image shapes the body. The resulting self-concept thus ignores a dynamic that is common in our everyday life. For an improved account of the narrative self, which presents a more accurate portrayal of the way in which we experience ourselves in dayto-day life, this interactive relation must be explicitly included. The next two sections are devoted to demonstrating how narratives influence the body.

\section{How narratives shape the body}

In all of the above-mentioned cases, the narrative self is presented as a product of something else. In the argument made by Thornton and Zahavi, the narrative comes forth from the body, which provides a spatio-temporal logical underpinning for the narrative sequence, or the first-person perspective. Menary, just as Zahavi, is

\footnotetext{
${ }^{10}$ A social-cultural dimension plays an equally constitutive role in the development of our self, but I can't pursue that perspective within the scope of this paper.
} 
emphatically hierarchical when he states that the 'self is primarily an embodied consciousness that engages with the world', and 'only later' does it attempt to weave together its various experiences, via narratives (p.77). And, even in Mackenzie's account, though she speaks of a "dialectical relationship between body and subjectivity" (2009, p.118), the movement explicitly described is from the body to the (narrative) self, as she focuses on how we are passive to certain aspects of our body (e.g. gender, genetically determined features), while these aspects of our embodiment nevertheless shape our identities. Though Mackenzie's account explicitly allows for the dynamic interaction that I intend to describe, there is no elaboration on that point in her account, nor are there specific examples or clarifications that would draw attention to the influence of our self-understanding on our embodiment. Such examples and clarifications would enhance our understanding of a dynamic self-concept.

In what follows I do not quarrel with the above claims about embodiment and the narrative self. However, without influence from narratives on our bodies, there is no full-blown dynamic interaction between self-narrative and embodiment. Whereas some accounts merely fail to dwell upon it, others explicitly rule out the possibility that our narrative influences other aspects of our being, such as our embodiment or experiences. Considering Dennett's commitment to materialism and his claim that the self is fictional, it is to be expected that Dennett thinks it impossible for the narrative self to change aspects outside itself (1992, p.110). ${ }^{11}$ However, it is not just Dennett who contends that an interactive relationship is impossible. Menary, too, who defends an embodied narrative self, denies the narrative any possible power over the embodied experiential subject:

First there are the experiences of a living body and then we turn those experiences into a narrative. [...] It's not narratives that shape experiences but, rather, experiences that structure narratives. Experiences are the sequence of events that give structure and content to narratives. [...] The mistake is again to suppose that a narrative conceived in abstraction could be brought to bear on a sequence of experiences, ordering them and giving them meaning. (Menary 2008, 78-79).

Apart from the obvious fact that in the very beginning of life we have a body and not yet our own narrative, and that a sound embodied first-person perspective is needed as a precondition, it is not the case that a narrative cannot shape particular experiences later on in life. I think a narrative can, and in doing so, alter the meaning - and thus the experience - of the experience.

To be clear about the different aspects of the self which interact with one another, I need a brief interlude to define - more specifically than the way I put it in the introduction — what I will take the term 'narrative self' to refer to. This is a topic which deserves a paper of its own, even more so since the various uses of the term have complicated the debate. However, outlining the salient characteristics suffices for the point I would like to make concerning the relationship between the narrative and the body. Before listing these characteristics, I need to make one important proviso: the

\footnotetext{
${ }^{11}$ This typifying of the self as an epiphenomenon seems to be inconsistent with Dennett's claim that the narrative self plays an important role as a cognitive model for our biological survival, since the latter seems to logically imply that the narrative self does something for our course of actions (1991, 427-428).
} 
view of the self as a dynamic interaction between its various aspects defended here may not fit perfectly under the header 'narrative self', since this term seems to express the idea that the self is only a narrative. Therefore it may be better to refer to the narrative aspect of the self as our narrative self-understanding. ${ }^{12}$ Narrative self-understanding has four defining characteristics:

1. By 'narrative self-understanding' I mean that we understand what we do and say diachronically, by embedding them in a larger stream of experiences with which they are meaningfully, rather than merely causally, connected. In other words, the meaningful structure of our experience and self-understanding entails a 'diachronic holism': new events get their meaning and sensibility within a context of earlier and expected events (Slors 2001). This understanding is not limited to cognitive states and perceptions, but also involves emotional states ${ }^{13}$;

2. Narrative self-understanding functions as one element of the background against which we understand our contact with others, what we do and say, or make up our mind when faced with, e.g., difficult decisions for our life course. As such it is one of the elements that constitute our selves.

3. Our narrative self-understanding often functions implicitly, but it can become (partly) explicit, for example, upon questioning - either by someone else or by oneself.

4. For the concept to be clear and of use, it is important that it is demarcated, to which I would add that it should remain tied to our identity. ${ }^{14}$ That is to say, a narrative about making coffee, or writing a paper, as such, does not belong to your narrative self-understanding, at least, as long as it does not capture something personal about who you understand yourself to be. ${ }^{15}$

Given this brief description, it can become clear that when my self-understanding - a framework within which I understand what I do and say - changes, I myself as an embodied subject may change as well. That is, the (implicit) description under which I

\footnotetext{
${ }^{12}$ This term, in turn, invites misunderstandings of its own. Most importantly, the term understanding; this may give rise to an exclusively cognitive reading. I hope to undermine some of these inappropriate connotations in the explanation that follows.

${ }^{13}$ I do not cling to the term "narrative"; perhaps this kind of self-understanding can also be termed, e.g., "diachronically meaningful self-understanding" - but I do not consider that term an improvement. However, I do cling to what I aspire to capture with the term as set out in the defining characteristics. Critics have argued that, when stripped of its unrealistic interpretations (such as the idea that one could or should live one's life as a well-structured novel), the concept of "narrative" turns out to be otiose. Critics such as Christman (2004; 2009) and Fisher (2010) suggest that, instead of the narrativity concept, we should use a more basic concept that captures our ability to interpret situations and our self in a meaningful way, such as "narratibility" (Fisher, 255) or "capacity for self-interpretation mediated by socially embedded rules of meaning" (Christman 2009, 83). However, I believe that the four characteristics that I present above make for a different and more specific notion than a more general "capacity for reflection" (Christman 2009, 78), which we also happen to use for interpreting ourselves. If all this can be more adequately captured with a different term, I would rather use that; until then, I will employ the term "narrative".

${ }^{14}$ Embedded in an intersubjective self-concept, narrative self-understanding always implies a relationship with the social world, which is why a narrative self-understanding also always involves some take on the world, thus forming an integral part of what can be referred to as one's Weltanschaaung.

${ }^{15}$ The writing example comes from Mackenzie (2007, p.269); the coffee-making example is discussed by Strawson (2004) and has often been referred to as an example of how the narrativity thesis becomes trivial or empty if not clearly demarcated.
} 
understand myself influences bodily aspects such as my posture and bodily habits. Numerous examples from daily life serve to illustrate this point. For example, consider a woman who has a poor impression of herself, who has the idea that she is a bore and should not be in other peoples' way; she enters a public space in a completely different manner - e.g. shoulders folded inward, avoiding eye contact - than a woman who believes she is the kind of person people tend to like. The latter may enter a room with a more open posture, daring to take up space and filling the room with her voice. ${ }^{16}$

Or consider again Mackenzie's example of the thin man who develops a fit and lean representation of himself as he develops into a cross-country runner. In this example, the man's self-understanding changes because of bodily changes. However, it could also have happened the other way around. Imagine that without (first) changing physically, the man changes his self-image through reflection. He may, for instance, realize that his representation of himself as puny and scrawny originates from being bullied when he was younger. However, he is now in a different environment where he has made new friends and gotten into a relationship. This all leads to his self-esteem growing and the realization that he does not have to see himself the way he does: it is a perspective rather than a fact of his being. These circumstances and the reflections that flow from them, can result in the young man altering his self-understanding: he may no longer see himself as puny. When his self-narrative changes in this way, this will affect his body. As in the previous example of the person with high self-esteem versus the one with low self-esteem, his changed self-understanding may become visible in a different posture, in his bodily traits.

In the example of the thin man, there are various experiences that inform a different narrative self-understanding, which subsequently give rise to a different bodily attitude. This sequence of events follows naturally from the fact that our narrative is substantially formed by events and experiences that we interpret. Yet alterations in various aspects of one's self can also begin with changes in one's narrative self-understanding. In fact, several therapies are based on the assumption that changing one's selfunderstanding will trigger change in one's experience and create space to change one's actions. In this process, the narrative is clearly the instigator rather than the result or the reporter of the change. Thus, under my interpretation of narrative self-understanding, it is not mistaken to claim that our narrative shapes our experiences and bodily traits; on the contrary, it shows there is an interactive influence between, on the one hand, our narrative self-understanding, and, on the other, our experiences and embodiment. To show how this may work, it is fruitful to consider an illustration of a case from the perspective of a psychotherapeutic method known as 'schema therapy'.

\section{A case illustration from psychotherapy}

Schema therapy is a form of psychotherapy that combines aspects of different approaches, regarding behavioural components as equally important to emotional change and the cognitive convictions that drive behaviour and emotions (Young et al. 2003).

\footnotetext{
${ }^{16}$ This is of course not to suggest that people with low esteem are always looking downwards, or that people with high esteem always dominantly take up space. The point is that these self-images result in bodily traits, of which these are possible outcomes.
} 
This integrating ambition fits well with the purported view of the self as an interaction between its different aspects. In general, the term 'schema' can in the psychotherapeutic context be understood as "any broad organizing principle for making sense of one's life experience" (Young et al. 2003, 7). Schemas concern a broad pattern or theme that run through various aspects of our self: they are comprised of cognitions, emotions, memories, and bodily sensations, and they concern oneself and one's relationships with others (Ibid). ${ }^{17}$ Every person develops these schemas; they are formed in early life, but continue to be elaborated and are superimposed on later life experiences, even when they may no longer be applicable. This is sometimes referred to as the need for 'cognitive consistency,' for maintaining a stable view of oneself and the world (Ibid). ${ }^{18}$

The general delineation of the schema concept is [in harmony with] the notion of narrative self-understanding as defined in the former section. For, (1) a sense-making principle that unfolds over the years is comparable to the diachronic framework of narrative self-understanding; (2) the applicability of schemas to actual experience is similar to the constitutive characteristic of narrative self-understanding: it shows how one's self-understanding shapes one's experience and interpretation of current events; (3) the schemas may be implicit, one aim of the therapy is to make them explicit so that they can be changed; (4) these schemas concern one's understanding of oneself, also in relation to the social world.

Although the four characteristics of narrative self-understanding are in harmony with the general description of a schema, the concepts are not the same. Each concept has been developed within a different context and serves different purposes: the concept of narrative self-understanding is developed within a philosophical debate aimed at a better grasp of the nature of the self; the concept of a schema is developed for psychotherapeutic purposes: it serves to identify psychological problems; it forms no part of an explicit self-concept, neither is there some clarification as to how this concept would implicitly relate to the notion of a self. More research would be needed to determine how exactly the notion of schema and narrative self-understanding relate to one another. In the context of this paper however, it suffices to note that in the field of psychology there exists a parallel view on the dynamic interaction between selfunderstanding that develops over the years and our embodiment. Moreover, examples taken from this therapeutic practice illustrate the point I am trying to make with respect to the influence of self-narratives on embodiment in a way that is much more concrete than a philosophical elaboration would be. Hence, let us consider a case from the practitioner's guide on schema therapy to see in which way convictions concerning oneself, influence bodily traits, experience, emotions, and behaviour.

Martine has what is referred to as a 'defectiveness schema': she has the feeling and belief that she is defective or inferior in important respects. In Martine's case this

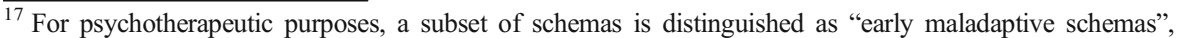
which are persistent and dysfunctional to a significant degree. When maladaptive, schemas are self-defeating emotional and cognitive patterns that begin in early development and repeat throughout life $(2003,7)$.

${ }^{18}$ Interestingly, Velleman also claims that our narrative self-identity (which he explains as a drive toward selfunderstanding) stems from a drive towards self-consistency. Velleman also argues that this drive toward selfconsistency leads us to bring our actions into line with our self-description, thus the self-narrative is not only an output, but also a source of action. However, Velleman's account of the self does not become truly embodied; rather it remains very cognitive and is actually in some respects close to Dennett's. (Velleman 2006. For a critical discussion, see Mackenzie 2007).
} 
resulted mostly from her relationship with her mother, who did not give Martine any love or recognition. When Martine (age 31) enters therapy, she has recently been introduced by her boyfriend, Johnny, to the women who are dating his friends. Martine likes these women very much, but, although they have been welcoming to her, she feels unable to establish friendships with them. She believes they do not like her, and gets "really nervous" when with them (Ibid, 30-31).

Cognitively, affectively, and behaviourally, Martine acts in such a way that she perpetuates her schema with these women. Cognitively, she distorts information so that it upholds her understanding of herself as defective. She discounts the many gestures of friendliness the women have made toward her ("They're only being nice because of Johnny. They don't really like me"), and falsely interprets the women's behaviour as evidence of their dislike. For example, when one of the women, Robin, did not ask Martine to be a bridesmaid in her upcoming wedding, Martine jumped to the conclusion that Robin "hated" her, even though she had known Robin for too short a time to be a likely candidate for a bridesmaid. Affectively, Martine has strong emotional responses to events that even slightly resemble her childhood schema triggers; she feels intensely upset at any perceived rejection, no matter how slight. When Robin did not ask her to be a bridesmaid, for example, Martine felt utterly worthless and ashamed. "I hate myself," she told her therapist. Also, Martine behaves differently towards the most critical of the women, with whom she moreover most actively seeks friendship. Just as she had towards her mother, Martine behaves deferentially and apologetically towards this woman (Ibid, 31).

What this case illustrates is that Martine's feelings of inferiority towards her mother have induced a particular understanding of herself which has become a framework in which she understands and experiences herself in relation to other people. What is crucially important is that Martine's self-understanding is not a purely cognitive affair; rather, it is thoroughly embodied: Martine approaches these women in a specific, tentative manner; it shows in how she moves between the group, how she uses her voice, how she makes or avoids eye contact. All these characteristics that are part of Martine's body-language are, at least in part, a direct consequence of Martine's selfunderstanding. Moreover, these bodily traits are crucial for the perpetuation of Martine's understanding of herself as inferior, which further displays the bidirectional relationship between self-understanding and embodiment. Embodiment may perpetuate the self-understanding in two possible ways. First, as dramatic cases can illustrate, one's attitude can turn into a self-fulfilling prophecy: e.g., someone who moves, looks, behaves as if being bullied, may have a bigger chance to indeed be illtreated by some people. More often though, the perpetuation works more subtly but powerfully nonetheless, in that a bodily attitude enforces the accompanying affective attitude, e.g., someone who carries herself as if uncomfortable, will be triggered to feel uncomfortable by this bodily comportment, which in turn works upon her experience of feeling uncomfortable (an idea that harks back to Darwin and James (1884) but that has been updated e.g. in Damasio 1994).

Equally important to note is that Martine's interpretations of the other women are not derivative products of neutral data; Martine perceives their rejection directly. She 'reads' the women in a specific manner, which is informed by the understanding of her self as inferior, and she responds to these interactions directly as well, emotionally, and behaviourally. This directness shows how one's self-understanding is constitutive 
for who one is and how one experiences life: it colours the way Martine perceives herself and her being in the social world.

Despite these (re-) enforcing influences, Martine is not fully determined by her former experiences. After all, the fact that she enters therapy shows that Martine must have some awareness of a friction between her attitude and the world, and perhaps the hope that this could be altered. Moreover, one goal of the therapy is to change distorting schemas that influence Martine's self-understanding, after which Martine's behaviour and affective responses hopefully change as well. Explicating parts of the implicit selfunderstanding and understanding how these originated and evolved, opens a path to their alteration. Personal change occurs at different levels, but in Martine's case surely one level of change is to try to 'understand' herself differently despite the bodily and affective response of defectiveness, so that, through this new framework, bodily and affective change can hopefully follow.

To conclude this section, Martine's case provides a glimpse of how the various aspects of our self are entangled, and, more specifically, how our self-understanding should be understood as one such aspect that is entangled with others, e.g. bodily and experiential, aspects of our self.

\section{Body and self in feminist philosophy and theory of mind}

As a final illumination of this interaction between narrative self-understanding and the self's embodiment, I would like to point to two different debates that provide fertile soil for this view of the self: the perspective on the body in feminist philosophy, and the debate on social cognition and theory of mind. The overlap between these debates may demonstrate that the notion of the self defended here does not deviate far from certain intuitions that some academic fields have already accepted.

One key theme in feminist philosophy is the way in which social and cultural notions such as gender, sexuality, and bodily ideals are incorporated in the experience of, and attitude towards, one's body. The general claim here is that a large amount of what is seen as characteristic of female behaviour and embodiment - as opposed to male behaviour and embodiment - is falsely considered to stem from some ahistorical, natural "feminine essence", some biological fact, whereas most of these traits are actually the result of social, cultural, historical, and economic factors. De Beauvoir (1949) and many feminist philosophers since have famously argued this point. The debate is imbued with nature-nurture questions, and surely not all issues are settled in this debate. Nevertheless, the point that at least a fair part of our embodiment is influenced by factors of a socio-cultural nature appears to be relatively uncontested. From here, it is not such a stretch to see how our - socio-culturally mediated - narrative self-understanding also influences our bodily traits. In fact, in her account of the narrative self, Mackenzie also alludes to feminist literature. ${ }^{19}$ Mackenzie emphasizes that "one also incorporates social and cultural meanings related to gender into one's bodily perspective and one's narrative self-conception" $(2009,118)$. She points to the way our body thus gets determined, not explicating how we can understand from this cultural influence on our body, in an analogous way, that our individual narrative self-

${ }^{19}$ Referring, among others, to Young's paper "Throwing like a girl” (1990). See: Mackenzie (2009). 
understanding equally shapes our bodily lives. However, if one agrees that sociocultural notions influence our embodiment, it seems equally possible that more personal notions concerning oneself influence our embodiment.

Another view that can be supportive for the bi-directional interaction between narrative self-understanding and the body can be distilled from the debate on social cognition. The pivotal question here is: how do we understand other people, or know what they think or feel, while not having direct access to their minds? In recent years, many philosophers have come to argue that this question is misleading, since it falsely presents the mental as some inner entity hidden in the body, and the body as an obstruction that hides away the inner. In fact, our understanding of what is going on in other people's minds is always mediated by their bodily behaviour. At the same time, this means that our basic acquaintance with others is not inferential, but rather straightforward: we can perceive anger, sadness, fright, or the having of questions or worries in someone's movements, facial expressions, gestures, and actions. ${ }^{20} \mathrm{We}$ can do so, because affective states are not only subjective experiences, but are actually present in expressive bodily gestures and actions, and thus visible to others. ${ }^{21}$ Illustrations of this direct interpretation mostly concern time slices of people's behaviour that convey their emotions or concerns.

The bottom line is that the inner and outer are integrated, which obviously fits well with the idea of interaction between our self-understanding and body. Additionally, the notion of narrative self-understanding may further our understanding of this more basic social cognition in two ways. ${ }^{22}$ Firstly, it can elaborate on the content of social cognition, what it is that we grasp when we understand others. Clearly our grasp stretches further than momentary fragments of behaviour; there are structural characteristics in people's behaviour, and over time these character traits become noticeable to others. As we saw in the case of Martine, aspects of her self-understanding shine through in bodily traits and behaviour. Beside other factors such as biological determinants, her self-understanding is thus one structuring factor for Martine's bodily traits and behaviour in particular contexts of which the people around her can become aware. In general, we know a person when we recognize his or her particular traits as characteristic for who (s)he is, an identity that we can make sense of in terms of the person's history and how (s)he has lived through that history, e.g., how it has shaped his/her outlook on the world and his/her self, and how it forms his/her experiences.

Secondly, the intertwining of the narrative self-understanding with our view on other people's behaviour, shows that how one understands others can be shaped to the extent of being distorted by our own narrative self-understanding. Again, in the case of Martine, her social cognition is partly distorted through her self-understanding. Of course her case is an extreme one; for most people the influence will be much more

\footnotetext{
${ }^{20}$ Cf. for an explanation of this stance: Gallagher \& Zahavi (2008, 181-187). References for this position include the work of Max Scheler (1954) and Merleau-Ponty (1962).

${ }^{21}$ The purported view of social cognition does not necessarily include the denial of an inner life; the point is, rather, that the mind is entangled with our embodiment and that for a sufficiently perceptive observer, someone's attitude or emotions are visible in these bodily aspects.

${ }^{22}$ Gallagher and Zahavi have also discussed narrativity as an addition to a more basic understanding of others. However, in this context they do not characterize narrative as part of one's self-understanding, as I do, from which follows a richer understanding of other people, but rather interpret it as a tool that helps us grasp the context in which we understand others $(2008$, p. 194).
} 
subtle. However, understanding social cognition as partly individually formed is an interesting insight for a richer understanding of how our social cognition is shaped.

\section{Summary and conclusion}

In this paper I argue for a conception of the narrative self as one aspect of the self, our narrative self-understanding, which dynamically interacts with our embodiment as well as with other aspects of our self. I also argue that within the debate on the narrative self no full-blown interactive account can be found, for typically the influence of selfnarratives on the body is at best only implied. A truly integrated notion of the embodied narrative self is therefore lacking. Upon reviewing one of the most well-known narrative self-concepts, Dennett's, an entirely disembodied account against the backdrop of its critics, I found that critics who have included the body in their account have done so as either a formal pre-condition, or, when made more personal, have still presented the relationship between the body and the narrative self as primarily unidirectional. Only by acknowledging an interactive relationship, however, can we begin to capture the way in which different aspects of the self are interwoven. The examples discussed, as well as the indicated similarity to some views in other academic debates on the relationship between our body and other aspects of our self, further illuminate some of the ways in which aspects of the self are interconnected.

In opposition to various doubts that have been raised about the narrative self-concept's relevance, this argument takes a stance against its triviality. ${ }^{23}$ For, if our narrative selfunderstanding works on everything from our course of actions down to the very basic aspects of our bodily posture, its relevance is obvious. Of course this is not to claim that the self is only narrative - by now it should be clear that we should aim to capture the self in its various, interacting, aspects; one of these being narrative self-understanding.

\section{References}

Atkins, K. (2004). Narrative identity, practical identity and ethical subjectivity'. Continental Philosophy Review, 37, 341-66.

Atkins, K. (2008). Narrative identity and embodied continuity'. In K. Atkins \& C. Mackenzie (Eds.), Practical identity and narrative agency (pp. 78-98). New York: Routledge.

Baker, L. R. (2000). Persons and Bodies: A Constitution View. Cambridge: Cambridge University Press.

de Beauvoir, S. (1949). The second sex. Trans. C. Borde and S. Malovany-Chevallier (2011). New York: Vintage Books.

Campbell, J. (1994). Past space and self. Cambridge, Massachusetts: MIT Press.

Christman, J. (2009). The politics of persons: individual autonomy and socio-historical selves. Cambridge: Cambridge University Press.

Christman, J. (2004). Narrative unity as a condition of personhood'. Metaphilosophy, 35(5), 695-713.

Damasio, A. (1994). Descartes' error: emotion, reason, and the human brain. New York: Penguin.

Damasio, A. (2010). When self comes to mind. Constructing the conscious brain. New York: Pantheon Books.

Dennett, D. (1991). Consciousness explained. New York: Back Bay Books.

Dennett, D. (1992). 'The self as a center of narrative gravity' in: Cole, P.M., F.S. Kessel and D.J. Johnson (eds.), Self and consciousness. Multiple perspectives (103-115). Lawrence Erlbaum Associates.

Fisher, T. (2010). Heidegger and the narrativity debate'. Continental Philosophical Review, 43, 241-265.

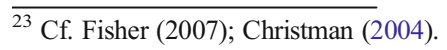


Gallagher, S., \& Zahavi, D. (2008). The phenomenological mind. An introduction to philosophy of mind and cognitive science. New York: Routledge.

Henry, M. (2003). De la subjectivité. Paris: PUF.

James, W. (1884). What is an Emotion?'. Mind, 9, 188-205.

Mackenzie, C. (2007). Bare personhood? Velleman on selfhood'. Philosophical Explorations, 10(3), 263-281.

Mackenzie, C. (2008). Introduction'. In K. Atkins \& C. Mackenzie (Eds.), Practical identity and narrative agency (pp. 1-28). New York: Routledge.

Mackenzie, C. (2009). Personal identity, narrative integration, and embodiment'. In S. Campbell, L. Meynell, \& S. Sherwin (Eds.), Embodiment and agency (pp. 100-125). Pennsylvania: Pennsylvania University Press.

McDowell, J. (1998). Mind value and reality. Cambridge, Massachusetts: Harvard University Press.

Menary, R. (2008). Embodied narratives'. Journal of Consciousness Studies, 15(6), 63-84.

Merleau-Ponty, M. (1962). Phenomenology of perception. New York: Routledge.

Metzinger, T. (2003). Being No One. Cambridge: MIT Press.

Ricoeur, P. (1992). Oneself as another. Chicago: The University of Chicago Press.

Sartre, J.-P. (1956). Being and Nothingness. New York: Trans. H. E. Barnes, Philosophical Library.

Schechtman, M. (1996). The constitution of selves. Ithaca New York: Cornell University Press.

Schechtman, M. (2007). Stories, lives, and basic survival: a refinement and defense of the narrative view'. In D. Hutto (Ed.), Narrative and understanding persons (pp. 155-178). Cambridge: Cambridge University Press.

Scheler, M. (1954). The nature of sympathy. London: Routledge and Kegal Paul.

Slors, M. (2001). Personal Identity, Memory, and Circularity: An Alternative for Q-memory'. The Journal of Philosophy, 98(4), 186-214.

Slors, M. (1998). Two conceptions of psychological continuity'. Philosophical Explorations, 1, 61-80.

Strawson, G. (2004). Against narrativity'. Ratio, 17(4), 428-452.

Strawson, P. F. (1959). Individuals. London: Methuen.

Taylor, C. (1989). Sources of the self. The making of the modern identity. Cambridge: Harvard University Press.

Thornton, T. (2003). Psychopathology and two narrative accounts of the self'. Philosophy, Psychiatry, \& Psychology, 10(4), 361-367.

Velleman, D. (2006). Self to self. Cambridge: Cambridge University Press.

Young, I. M. (1990). Throwing like a girl'. In Throwing like a girl and other essays in feminist philosophy and social theory (pp. 141-159). Bloomington: Indiana University Press.

Young, J. E., Klosko, J. S., \& Weishaar, M. E. (2003). Schema therapy: a practitioner's guide. New York: The Guilford Press.

Zahavi, D. (2005). Subjectivity and selfhood. Investigating the first-person perspective. Cambridge: MIT Press.

Zahavi, D. (2007). Self and other: the limits of narrative understanding'. In D. Hutto (Ed.), Narrative and understanding persons (179-201). Cambridge: Cambridge University Press. 